SHORT REPORT

\title{
Weight differences in Plymouth toddlers compared to the British Growth Reference Population
}

\author{
E Stenhouse, D E Wright, A T Hattersley, B A Millward
}

Arch Dis Child 2004;89:843-844. doi: 10.1136/adc.2003.041061

Routinely collected weight measurements from 4665 Plymouth children born 1996-97 were compared with the British Growth Reference Charts (BGRC). The children were 0.33 SDS heavier on average than the reference population at 24-30 months, an actual excess of $460 \mathrm{~g}$.

$\mathrm{T}$ he epidemic of obesity has already been documented in adolescence, and even in children of school age. ${ }^{1-3}$ Few studies have systematically found younger children to be overweight. This study shows that by 24-30 months of age, children in Plymouth are already significantly fatter than the reference population. Fat children are likely to become fat adults, with attendant high morbidity and mortality. ${ }^{4}$

We aimed to compare birth weight, weight up to 24-30 months, and length/height at 24-30 months in a large Plymouth cohort with the British Growth Reference Charts (BGRC) derived in a similar way to see when contemporary children become heavier and to some degree fatter.

\section{METHODS}

The Plymouth Child Health Data-Base (PCHDB) contains data collected routinely from birth to school entry on all children born since 1988. We have validated two years of data for 1996 and 1997 from this database as part of a larger study investigating features of the fetal environment that may influence postnatal catch up or down growth. We have examined all available weight measurements from birth, $1 \frac{1}{2}-2$ months, 6-9 months, and 24-30 months, and height at $1 \frac{1}{2}-2$ months, 6-9 months, and 24-30 months from the developmental measurements made at the child surveillance clinics and held on the PCHDB.

We studied 4665 Caucasian children (2317 girls) born in the Plymouth catchment area between 1 January 1996 and 31 December 1997. The data were cleansed by removing children whose measurements fell outside 5 SD for height or weight and those not of Caucasian background. By using the linked software program supplied by the Child Growth Foundation UK, ${ }^{5}$ standard deviation scores (SDS) for weight and height were calculated for all children at all time points. The BMI $\left(\mathrm{wt}(\mathrm{kg}) /\right.$ height $\left.(\mathrm{m})^{2}\right)$ was calculated only for children at 24-30 months, when the accuracy of height measurement is thought to be reliable and accurate because this is the age when infants can stand unaided.

\section{RESULTS}

The weights of Plymouth children were similar to those of the reference population at birth, 1 1 $12-2$ months, and 6-9 months, with the mean SDS and standard deviations not differing significantly from the reference population (table 1). There were also no significant differences between boys and girls (data not shown). However, by 24-30 months the SDS for weight in Plymouth children was significantly greater than that of the reference population (mean weight excess of 460 g (95\% CI 420 to 510$)$ ).

Table 1 shows the excess BMI SDS for boys and girls at 2430 months to be 0.26 (95\% CI 0.22 to 0.3 ). The mean excess height SDS at the same time was 0.14 (95\% CI 0.01 to 0.17 ). This change is insufficient to explain the BMI SDS excess. Therefore, these figures suggest a significant increase in weight due to fatness. The fluctuating height SDS $(0.38,0.41$, and 0.14) may be due to the inherent inaccuracies in the method of measuring height below 24 months. The SD of the SDS was close to 1 in all measures, which indicated the data are robust.

\section{DISCUSSION}

The observation that contemporary Plymouth toddlers, as young as 24-30 months of age, are heavier and fatter than the reference population is an important one, and a cause for concern. Although children at school entry have been documented to be overweight, ${ }^{6}$ it is alarming to see that such young children as described here are on average $460 \mathrm{~g}$ heavier by around 2 years of age than the reference population. Environmental factors in the pre- and post-natal periods are likely to account for this observation. There were no significant changes in weight until 24-30 months of age, a time by which most infants will have been weaned. In addition, toddlers may also be getting less physical activity

Table 1 Mean SDS, 95\% Cl, and SD for 1996 and 1997 male and female Plymouth cohort produced from the British Growth Reference Charts

\begin{tabular}{llllll}
\hline Measurement & Age & $\mathbf{n}$ & Mean SDS & (95\% CI) & SD \\
\hline Weight & Birth & 4665 & 0.03 & $(0.00$ to 0.05$)$ & 0.93 \\
& $11 / 2-2$ months & 3607 & 0.02 & $(-0.02$ to 0.05$)$ & 0.95 \\
& $6-9$ months & 3625 & 0.02 & $(-0.05$ to 0.02$)$ & 1.01 \\
Height & $24-30$ months & 3164 & 0.33 & $(0.29$ to 0.36$)$ & 0.95 \\
& $11 / 2-2$ months & 3515 & 0.38 & $(0.34$ to 0.41$)$ & 1.07 \\
BMI & 6-9 months & 3676 & 0.41 & $(0.37$ to 0.44$)$ & 1.09 \\
& $24-30$ months & 2941 & 0.14 & $(0.1$ to 0.17$)$ & 1.04 \\
& $24-30$ months & 2829 & 0.26 & $(0.23$ to 0.3$)$ & 0.99 \\
\hline
\end{tabular}


compared to those of a generation ago. Thus, this may be a critical time where at least two important environmental changes have occurred which may be contributing to toddlers' weight gain. If this is the case, then it is conceivable that as a society we could reverse this change.

In data not presented in this paper we have validated many aspects of routinely collected data. These studies along with this present study have shown that it is possible to use simple, easily acquired anthropometric measurements of weight and height, taken as part of routine child surveillance, to provide robust and valuable information to answer research questions. In this way, it is possible to use very large numbers of measurements collected cost effectively.

\section{Authors' affiliations}

E Stenhouse, B A Millward, Molecular Medicine Research Group, Institute of Biomedical and Clinical Science, Peninsula Medical School, Plymouth, UK

D E Wright, Department of Mathematics and Statistics, University of Plymouth, Plymouth, UK
A T Hattersley, Diabetes and Vascular Medicine, Institute of Biomedical and Clinical Science, Peninsula Medical School, Exeter, UK

Correspondence to: $\operatorname{Dr} B$ A Millward, Senior Lecturer/Consultant in Diabetes, Room N32 ITTC Building, Tamar Science Park, 1 Davy Road, Derriford, Plymouth PL6 8BXX, UK; ann.millward@pms.ac.uk

Accepted 28 January 2004

\section{REFERENCES}

1 Bundred P, Kitchener D, Buchan I. Prevalence of overweight and obese children between 1989 and 1998: population based series of cross sectional studies. BMJ 2001;322:326-33.

2 McCarthy HD, Ellis SM, Cole TJ. Central overweight and obesity in British youth aged 11-16 years: cross sectional surveys of waist circumference. BMJ 2003;326:624.

3 Rudolf MCJ, Sahota P, Barth JH, et al. Increasing prevalence of obesity in primary school children: cohort study. BMJ 2001;322:1094-5.

4 Pi-Sunyer FX. Medical hazards of obesity. Ann Int Med 1993;1 19:655-60.

5 Child Growth Foundation. UK cross-sectional reference data: 1990/1.

London: Child Growth Foundation, 1996.

6 Wilkin TJ, Metcalf BS, Murphy MJ, et al. The relative contributions of birth weight, weight change, and current weight to insulin resistance in contemporary 5 year old: the Earlybird study. Diabetes 2002;51:3468-72.

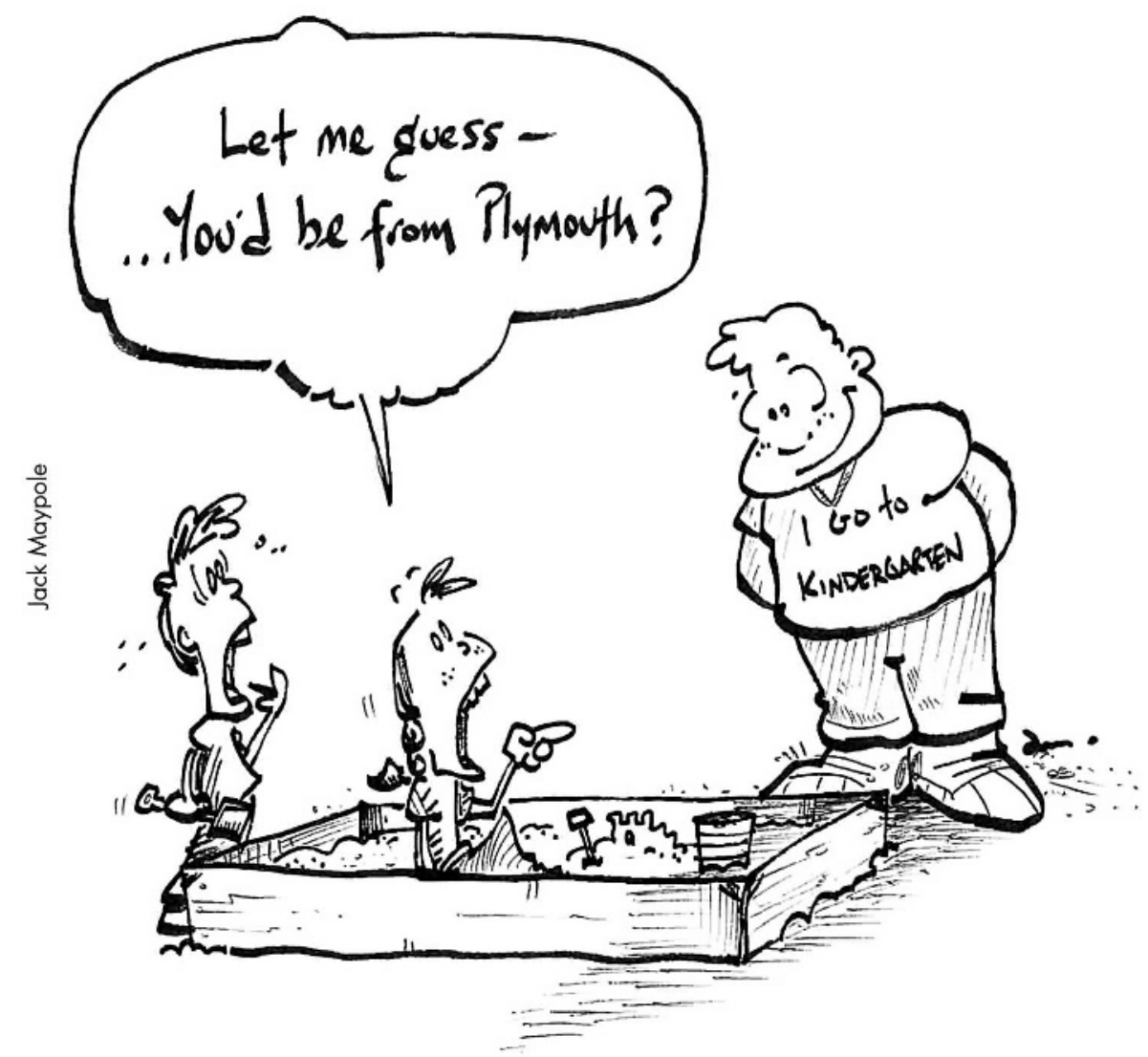

